\title{
Un balance institucional del desafío que ha significado la pandemia de COVID-19 en el 2020
}

\section{An institutional assessment of the challenge posed by the COVID-19 pandemic in 2020}

\author{
Luis Enrique Podestá Gavilano ${ }^{1, a}$ \\ Decano, Facultad de Medicina, Universidad Nacional Mayor de San Marcos. Lima, Perú. \\ a Doctor en Ciencias de la Salud, Profesor Principal de la Facultad de Medicina de la Universidad Nacional Mayor de San Marcos. ORCID: https://orcid.org/0000-0003-0122-8835
}

\author{
Correspondencia: \\ Luis Enrique Podestá Gavilano \\ Ipodestag@unmsm.edu.pe
}

Recibido: 31 de diciembre 2020

Aprobado: 22 de enero 2021

Publicación en línea: 15 de febrero 2021

Conflictos de interés: El autor declara no tener conflictos de interés

Fuente de financiamiento: Autofinanciado

Citar como: Podestá L. Un balance institucional del desafío que ha significado la pandemia de COVID-19 en el 2020. An Fac med. 2020;81(4):389-90. DOl: https:// doi.org/10.15381/anales.v81i4.20452
La actual pandemia del COVID-19 ha significado el más importante desafío que enfrenta nuestro país en este siglo $X X I$. En ningún momento de la historia de la República se han perdido tantas vidas peruanas en tan poco tiempo y los impactos económicos y sociales como lo señala la CEPAL han significado un retroceso importante en el desarrollo de nuestros países ${ }^{(1)}$. Esta pandemia ha ocasionado mucho dolor entre nosotros y nos ha llevado a vivir en un tiempo nuevo, a una forma diferente de vivir con profundos cambios en la esfera personal, familiar y en nuestra actividad académica y profesional.

Frente a este enorme desafío, la Facultad de Medicina de San Fernando, tuvo que movilizar el esfuerzo del conjunto de nuestra comunidad académica, lo que permitió poner en valor un conjunto de desarrollos previos para desplegar la mayoría de sus actividades en plataformas virtuales y en un tiempo breve, con el esfuerzo mancomunado de autoridades, docentes y alumnos, se pudo migrar gran parte de las actividades académicas y procesos técnico administrativos a un formato virtual según los estándares de la Superintendencia Nacional de Educación Superior Universitaria (SUNEDU). Para ello se desarrolló un programa intensivo de capacitación a fin de fortalecer las competencias de los equipos docentes en el manejo de diversas herramientas para la docencia en entornos virtuales. En total lograron implementarse en el último año académico 2020, 345 aulas virtuales para los estudios de pre-grado y 620 para los estudios de post-grado, lo cual constituye todo un hito en el desarrollo de nuestra institución. Asimismo, nuestra Facultad, con el invalorable apoyo solidario de la Peruvian American
Medical Society (PAMS) -Capítulo San Fernando- y de la Fundación Grunenthal, logró la adquisición de tablets y conectividad para estudiantes con barreras de acceso al internet.

Sin embargo, no solamente logramos sacar adelante nuestras actividades docentes, en medio de la crisis sanitaria nuestra facultad desarrolló algunas iniciativas de innovación. La Unidad de Telesalud de nuestra Facultad, quien antes de la pandemia era ya un referente para otras universidades por el apoyo a nuestros egresados que cursan el Servicio Rural y Urbano Marginal de Salud (SERUMS), en esta etapa ha tenido un papel importante en el ámbito del seguimiento remoto de pacientes afectados por esta pandemia a partir del trabajo voluntario de estudiantes. Un elemento importante fue el desarrollo de acciones de tele-monitoreo y tele-orientación a los pacientes miembros de nuestra comunidad universitaria.

Un logro importante, es el desarrollo de diversas iniciativas de investigación en el marco de esta pandemia. Un reconocimiento especial merece el esfuerzo de un grupo de investigadores docentes y alumnos voluntarios que impulsaron nuestra participación en el ensayo clínico de fase III de una vacuna contra el COVID-19 (2), lo que significó el reclutamiento y seguimiento de 4500 voluntarios actualmente en curso. Consideramos que el desarrollo de todas estas iniciativas será un aporte importante al conocimiento de la enfermedad en nuestro país.

El año 2021 es un año de especial significado por el bicentenario de la República. En medio de una grave crisis sanitaria, la Facultad de Medicina de San Fernando asume este desafío con gran responsabilidad. Así como hace 200 años, 
nuestra comunidad académica vivió un momento similar, en medio de la crisis e incertidumbre, San Fernando apostó por el sueño de una joven República y siendo consecuentes con ese compromiso, nuestra facultad espera el 2021 seguir avanzando en la innovación y mejora de la educación superior en salud, con 5 ejes estratégicos: el desarrollo en pre grado, posgrado, investigación, responsabilidad social, y la modernización administrativa, recogiendo las múltiples lecciones que nos ha dejado esta pandemia y de este modo contribuir al fortalecimiento de la salud pública del país.
No podemos dejar de recordar y rendir homenaje a los miembros de nuestra comunidad académica, docentes, trabajadores y estudiantes que nos dejaron en esta pandemia, nuestra solidaridad y afecto a sus familias. Nuestro profundo reconocimiento a las decenas de egresados de diversas promociones sanfernandinas que han fallecido heroicamente por su trabajo en la primera línea de lucha contra la pandemia de COVID-19, su sacrificio se suma al legado de generaciones de fernandinos que no dudaron en ofrecer su máximo esfuerzo; para servir al Perú en los momentos más difíciles de la vida de la República. Su recuerdo nos inspira a redoblar nuestro compromiso con el desarrollo de la facultad y del país.

\section{REFERENCIAS BIBLIOGRÁFICAS}

1. Bárcena A, Cimoli M. Economía global y desarrollo en tiempos de pandemia: Ios retos para América Latina y el Caribe. Revista CEPAL (Comisión Económica para América Latina y el Caribe). 2020; 132:9-16.

2. Diario El Comercio [Internet]. UNMSM se prepara para ensayos clínicos de posibles vacunas contra el COVID-19; 22 de agosto 2020 [Fecha de acceso: 30 de diciembre 2020]. Disponible en: https://elcomercio.pe/lima/sucesos/vacuna-covid-19-unmsm-seprepara-para-ensayos-clinicos-de-posibles-vacunascontra-el-coronavirus-sinopharm-peru-nndc-noticia/ 